\title{
Editor
}

Joe Bouch

Editorial Board Gwen Adshead J.S. Bamrah

Dinesh Bhugra Nick Brown

Patricia Casey

David Castle

John Cookson

Jonathan Green

Sheila Hollins

$\begin{array}{ll}\begin{array}{ll}\text { Cornelius Katona } \\ \text { Helen Killaspy }\end{array} & \begin{array}{l}\text { Editorial Assistants } \\ \text { Jonica Thomas } \\ \text { Femi Oyebode } \\ \text { Jan Scott }\end{array} \\ \begin{array}{ll}\text { Sophie Worth } \\ \text { Tom Sensky }\end{array} & \text { Staff Editors } \\ \text { Steven Sharfstein } & \text { Kasia Krawczyk } \\ \text { Michael Smith } & \text { Lynnette Maddock } \\ \text { Peter Tyrer } & \text { Zosia O'Connor } \\ \text { David Yeomans } & \end{array}$

David Yeomans

\section{Areas of uncertainty}

\author{
By Joe Bouch
}

In agreeing with John Williams of the Wellcome Trust that 'mental health is complex, nuanced [with] ethical, societal and sociological components' (Bithell, pp. 82-84), many of us will recognise what attracted us to specialise in psychiatry. But this description may also reveal why psychiatrists avoid engaging with the media. We fear the lack of understanding and strong preconceptions of both journalists and the public. We fear that we have few simple messages to give. And yet, as Bithell points out, 'the same issues that create communication challenges also make the field attractive to the media; areas where there are information gaps, debate, uncertainty and complexity tend to make great news and media features'. These areas of uncertainty are of key importance for Advances. Although 'science is our best way of knowing' (Opel 2111), there is no guarantee of high-quality evidence to inform clinical practice. A critical function of the journal is to aid our thinking where the evidence base is weak or where there is controversy. Commentaries are one means by which Advances can do this. Brown (pp. 101-103) exemplifies this approach. He emphasises the importance of physical environment, psychosocial interventions and teamwork alongside drug treatments in the management of severe agitation. Case reports may be another means.

Case reports have a chequered history in the academic literature but may be making a comeback. Some of the reasons for this are examined in a thoughtful editorial announcing the launch of a new surgical journal devoted to them (Agha 2010). Some might side with Bradford Hill, that statisticians 'may tend to be a trifle too scornful of the clinical judgement'; others with Shuster, that 'there are lies, damned lies and clinical impressions'. But Agha $\&$ Roisin wisely advise that both formal and informal evaluations of care are essential and complementary. They highlight the usefulness of the case report in discussing 'diagnostic approach, the context, background, decision-making, reasoning and outcomes'. Such usefulness has not been lost on medical educationalists. Case-based discussion (Brown et al, pp. 85-90) has become an important 'assessment of reasoning, exploring why a psychiatrist took a particular course of action at a particular time'. Used in both foundation and specialty training, it is also employed by the General Medical Council and the National Clinical Assessment Service when there are concerns about a doctor's performance.

\section{Race, ethics and personality disorder}

My Editor's Pick for this issue of Advances shows the educational value of a case report (Sen $\&$ Ramaswami, pp. 139-141). It would be instructive - and a worthwhile CPD exercise - first to read Undrill \& Gregory (pp. 131-138), who reflect on factors that contribute to team functioning, good and bad. Then read Sen \& Ramaswami's case report, which demonstrates how highquality team working was essential to managing a thorny clinical problem. And finally consider the set of questions (Box 1, p. 88) that might be asked in case-based discussion (Brown et al, pp. 85-90).

Agha R, Rosin RD (2010) Time for a new approach to case reports. International Journal of Surgery 8: 330-2.

Opel DJ, Diekema DS, Marcuse EK (2011) Assuring research integrity in the wake of Wakefield. BMJ 342: $179-80$. 